\title{
Palpitations in a 19-year old man and a slow heart rate at rest
}

\author{
A. A. M. Wilde
}

Published online: 23 April 2013

(C) The Author(s) 2013. This article is published with open access at Springerlink.com

A 19-year-old young man presents in your outpatient clinic with a history of palpitations. He had had one episode a few weeks ago but that episode terminated spontaneously. Another, more recent episode, had to be terminated in the hospital.

His medical history is unremarkable and his family history reveals a pacemaker implant at age 42 in his mother's brother. Physical examination reveals no abnormalities. His ECG is shown in Fig. 1. What would be your diagnosis?

\section{Answer}

You will find the answer elsewhere in this issue.

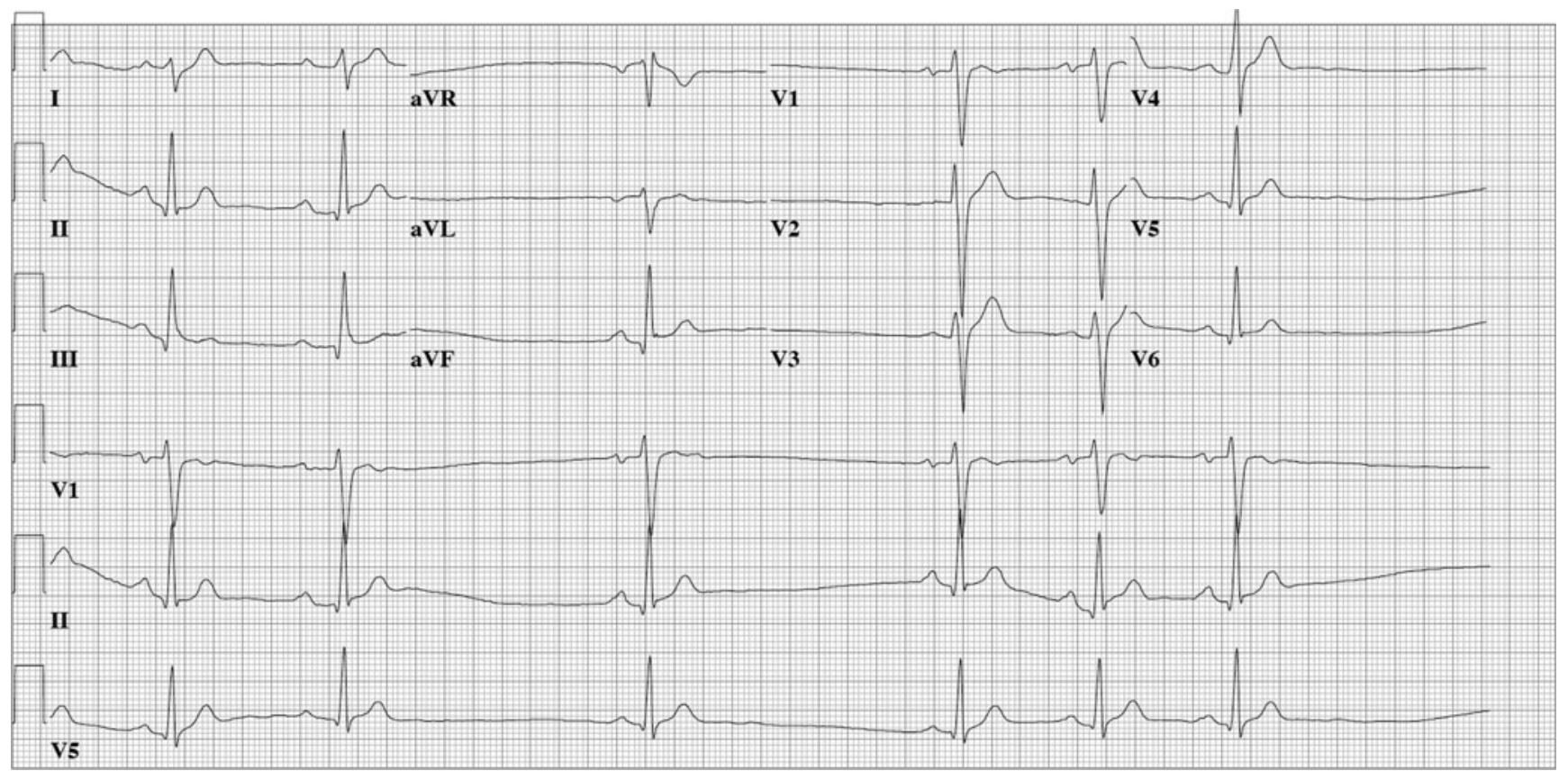

Fig. 1 ECG at presentation

A. A. M. Wilde $(\bowtie)$

Department of Cardiology, Academic Medical Center, Meibergdreef 9, 1105 AZ Amsterdam, the Netherlands e-mail: a.a.wilde@amc.uva.nl
Open Access This article is distributed under the terms of the Creative Commons Attribution License which permits any use, distribution, and reproduction in any medium, provided the original author(s) and the source are credited. 